https://journal-computing.org/index.php/journal-cisa/index

\title{
Rancang Bangun Sistem Manajemen Pengelolaan Pengaduan Masyarakat Di Kabupaten Kudus
}

\author{
Trendy Wijayanti ${ }^{1}$, Fajar Nugraha ${ }^{2}$, Andy Prasetyo Utomo ${ }^{3}$ \\ ${ }^{1}$ Information System Departement, Muria Kudus University, Kudus, Indonesia \\ 2,3Information System Departement, Muria Kudus University, Kudus, Indonesia \\ Email: 1201753092@std.umk.ac.id, 2fajar.nugraha@umk.ac.id, 3andy.prasetyo@umk.ac.id
}

\begin{abstract}
ABSTRAK
Pengaduan Masyarakat merupakan suatu sumber informasi yang sangat penting bagi upaya-upaya pihak penyelenggara pelayanan untuk memperbaiki kesalahan yang mungkin terjadi, sekaligus secara konsisten menjaga dan meningkatkan pelayanan yang dihasilkan agar selalu sesuai dengan standar yang ditetapkan. Satuan Polisi Pamong Praja (Satpol PP) Kudus merupakan tempat pelayanan pengaduan kepada masyarakat Kabupaten Kudus. Dalam hal pengaduan tentang ketertiban umum dan ketentraman masyarakat, masyarakat yang ingin melakukan pengaduan kejadian masih secara manual yaitu masyarakat datang kekantor Satpol PP Kabupaten Kudus, sehingga memerlukan suatu inovasi layanan agar memudahkan masyarakat dalam pengaduan. Inovasi tersebut ialah sistem informasi manajemen pengelolaan pengaduan masyarakat kabupaten kudus. Dengan suatu sistem informasi manejemen akan lebih membantu mempermudah instansi dalam proses operasional pelayanan pengaduan. Sistem ini menggunakan metode pengumpulan data dan dibuat menggunakan bahasa pemograman PHP dan database MySQL.
\end{abstract}

Kata kunci: Pengaduan, operasional, sistem informasi manajemen.

\section{PENDAHULUAN}

Satuan Polisi Pamong Praja (Satpol PP) Kudus merupakan tempat pelayanan pengaduan kepada masyarakat Kabupaten Kudus. Dalam hal pengaduan tentang ketertiban umum dan ketentraman masyarakat, masyarakat yang ingin melakukan pengaduan kejadian masih secara manual yaitu masyarakat datang kekantor Satpol PP Kabupaten Kudus, masyarakat melakukan pengaduan melalui social media, masyarakat yang mempunyai nomor pegawai Satpol PP Kabupaten Kudus bisa mengirim pesan via whattsap. Sehingga proses penanganan pengaduan tentang ketertiban umum dan ketentraman masyarakat menjadi kurang cepat atau 
Vol. 3, No. 1, January 2022 e-ISSN: 2775-2496

https://journal-computing.org/index.php/journal-cisa/index

lambat serta tidak efisien dibandingkan dengan teknologi komputerisasi berbasis web kepada pegawai serta notifikasi aplikasi mobile kepada masyarakat untuk memudahkan apakah pengaduan sudah tertanggani yang dari masa kemasa berkembang semakin pesat serta efektif dan proses lebih cepat.

Pengaduan masyarakat pada Satpol PP Kabupaten Kudus dimana salah satu kegiatan kerjanya yaitu menangani pelayanan pengaduan masyarakat yang melapor tentang ketertiban umum dan ketentraman masyarakat. Pada proses pengaduan masyarakat yang melapor kejadian datang langsung ke Kantor Satpol PP Kabupaten Kudus atau melalui via whattsap kepada pegawai Satpol PP Kabupaten Kudus dan memalui social media seperti twitter, instagram, facebook, dll. sehingga proses penanganan kurang efisien, serta masyarakat tidak tau apakah pengaduan kejadian tersebut sudah ditanggani atau tidak tertanggani. Selain itu, masalah yang menghambat pada proses pengaduan masyarakat yaitu data laporan pengaduan tidak terstruktur dengan rapi dan masih berantakan sehingga pada saat pengecekan data pengaduan masyarakat yang sudah ditanggani dan belum ditangani proses pencariannya sulit atau bahkan hilang. Oleh sebab itu, diperlukan sistem informasi yang berfungsi untuk mempercepat pengelolaan pengaduan masyarakat pada Satpol PP Kabupaten Kudus.

Penelitian ini membuat Sistem Informasi Manajemen Pengelolaan Pengaduan Masyarakat Kabupaten Kudus sebagai solusi untuk membantu instansi terkait dalam proses operasional pelayanan pengaduan.

\section{KERANGKA TEORI}

\subsection{Pengertian Sistem Informasi}

Sistem Informasi adalah kumpulan atau susunan yang terdiri dari perangkat keras dan perangkat lunak serta tenaga pelaksanaanya ang bekerja dalam sebuah proses berturutan dan secara bersama-sama saling mendukung untuk menghasilkan suatu produk.(Dengen, 2009).

\subsection{Pengertian Manajemen}

Manajemen berasal dari kata "to manage" yang artinya mengatur, pengaturan dilakukan melalui proses dan diatur berdasarkan urutan dari fungsi-fungsi manajemen itu, jadi manajemen itu merupakan suatu proses untuk mewujudkan tujuan yang diinginkan. (Hasibuan, 2004). 
Vol. 3, No. 1, January 2022 e-ISSN: 2775-2496

https://journal-computing.org/index.php/journal-cisa/index

\subsection{Pengertian Pengelolaan}

Pengelolaan merupakan istilah yang dipakai dalam ilmu manajemen, secara etomologi istilah pengelolaan berasal dari kata kelola (to manage) dan biasanya merujuk pada proses mengurus atau menangani sesuatu untuk mecapai tujuan terterntu. Jadi pengelolaan merupakan ilmu manajemen yang berhubungan dengan proses mengurus dan menangani sesuatu untuk mewujudkan tujuan tertentu yang ingin dicapai. (Nugroho, 2003.

\subsection{Pengertian Pengaduan Masyarakat}

Pengaduan Masyarakat merupakan suatu sumber informasi yang sangat penting bagi upaya-upaya pihak penyelenggara pelayanan untuk memperbaiki kesalahan yang mungkin terjadi, sekaligus secara konsisten menjaga dan meningkatkan pelayanan yang dihasilkan agar selalu sesuai dengan standar yang ditetapkan. (Agus Fanar Syukri, Ph.D.,2009.

\section{METODOLOGI PENELITIAN}

\subsection{Metode Pengembangan Sistem}

Metode pengembangan sistem adalah proses yang penting bagi pembuatan suatu aplikasi sistem. Dalam pengembangan yang diterapkan pada penelitian ini adalah model SDLC (System Development Life Cycle) atau sering juga disebut metode waterfall. Menurut Sukamto dan Shalahuddin (2018), waterfall menyediakan pendekatan alur hidup perangkat lunak secara sekuensial dimuali dari analisis, desain, pengkodean, pengujian, dan tahap pendukung (support).

Tahapan dari pengembangan sistem dalam metode waterfall antara lain:

1) Analisa kebutuhan perangkat lunak

Analisa kebutuhan perangkat lunak adalah proses pengumpulan kebutuhan dilakukan secara intensif untuk menspesifikasikan kebutuhan perangkat lunak agar dapat dipahami perangkat seperti apa yang dibutuhkan oleh pengguna. Spesifikasi kebutuhan perangkat lunak pada tahap ini perlu untuk didokumentasikan.

2) Desain perangkat lunak

Desain perngkat lunak adalah proses multi langkah yang focus pada desain pembuatan program perangkat lunak termasuk struktur data, arsitektur perangkat lunak, representasi antarmuka, dan prosedur pengkodean. Tahap ini mentranslasi kebutuhan perangkat lunak dari 
Vol. 3, No. 1, January 2022 e-ISSN: 2775-2496

https://journal-computing.org/index.php/journal-cisa/index

tahap analis kebutuhan ke representasi desain agar dapat diimplementasikan menjadi program pada tahap selanjutnya. Desain pernagkat lunak yang dihasilkan pada tahap ini juga perlu didokumentasikan.

3) Pembuatan kode program

Pembuatan kode program adalah desain harus ditranskasikan kedalam program perangkat lunak. Hasil dari tahap ini adalah program computer sesuai dengan desain yang telah dibuat pada tahap desain.

4) Pengujian

Pengujian focus pada perangkat lunak secara dari segi logic dan fungsional dan memastikan bahwa semua bagian sudah diuji. Hal ini dilakukan untuk meminimalisir kesalahan (error) dan memastikan keluaran yang dihasilkan sesuai dengan yang diinginkan.

5) Pendukung atau pemeliharaan

\subsection{Metode Perancangan Sistem}

Perkembangan teknik pemograman berorientasi objek, bahasapemodelan untuk pembangunan penelitian perangkat lunak yang dibangun dengan menggunakan teknik pemograman berorientasi objek, yaitu Unified Modelling Languange (UML).UML muncul karena adanya kebutuhan pemodelan visual untuk menspesifikasikan, menggambarkan, membangun, dan dokumentasi dari sitem perangkat lunak.Unified Modelling Languangemerupakan bahasa visual untuk pemodelan dan komunikasi mengenai sebuah sistem dengan menggunakan diaram dan teks-teks pendukung. Sukamto dan Shalahuddin (2018).

\section{HASIL DAN PEMBAHASAN}

Use case diagram merupakan pemodelan untuk kelakuakn (behavior) sistem informasi yang akan dibuat. Use case digunakan untuk mengetahui fungsi apa saja yang ada di dalam sistem informasi dan siapa saja yang berhak menggunakan fungsi-fungsi tersebut. Hendini (2016).

\subsection{Bussiness Use Case Diagram}

Proses bisnis yang ada pada Sistem Informasi Manajemen Pengelolaan Pengaduan Masyarakat pada Kabupaten Kudus dapat dilihat pada tabel 1 berikut. 
Vol. 3, No. 1, January 2022 e-ISSN: 2775-2496

https://journal-computing.org/index.php/journal-cisa/index

Tabel 1. Bussiness Use Case Diagram

\begin{tabular}{|c|c|c|c|}
\hline No & Proses Bisnis & Aktor & Business Use Case \\
\hline 1 & $\begin{array}{l}\text { Masyarakatt } \\
\text { mengajukan } \\
\text { pengaduan ke petugas } \\
\text { satpol PP }\end{array}$ & Masyarakat & $\begin{array}{l}\text { Mangajukan } \\
\text { pengaduan }\end{array}$ \\
\hline 2 & $\begin{array}{l}\text { Admin memverifikasi } \\
\text { pengaduan dari } \\
\text { masyarakat }\end{array}$ & Admin & $\begin{array}{l}\text { Verifikasi } \\
\text { pengaduan }\end{array}$ \\
\hline 3 & $\begin{array}{l}\text { Admin } \\
\text { menginformasikan } \\
\text { laporan pengaduan ke } \\
\text { petugas satpol pp }\end{array}$ & Admin & $\begin{array}{l}\text { Menginformasikan } \\
\text { Laporan } \\
\text { pengaduan }\end{array}$ \\
\hline 4 & $\begin{array}{l}\text { Petugas satpol PP } \\
\text { Kabupaten mengecek } \\
\text { laporan apakah perlu } \\
\text { bantuan ke Satpol PP } \\
\text { Kecamatan yang } \\
\text { terkait atau tidak. }\end{array}$ & $\begin{array}{l}\text { Petugas Satpol } \\
\text { PP Kabupaten }\end{array}$ & Mengecek Laporan \\
\hline 5 & $\begin{array}{lr}\text { Petugas satpol } & \text { PP } \\
\text { Kabupaten } & \text { dan } \\
\text { Kecamatan } & \\
\text { melakukan } & \\
\text { penanganan } & \\
\text { pengaduan } & \\
\end{array}$ & $\begin{array}{l}\text { Petugas Satpol } \\
\text { PP Kabupaten } \\
\text { dan Kecamatan }\end{array}$ & $\begin{array}{l}\text { Penanganan } \\
\text { Pengaduan }\end{array}$ \\
\hline 6 & $\begin{array}{l}\text { Petugas satpol PP } \\
\text { Menulis laporan hasil } \\
\text { pengaduan }\end{array}$ & $\begin{array}{l}\text { Petugas Satpol } \\
\text { PP Kabupaten } \\
\text { dan Kecamatan }\end{array}$ & $\begin{array}{ll}\text { Pelaporan } & \text { Hasil } \\
\text { Pengaduan } & \end{array}$ \\
\hline 7 & $\begin{array}{lr}\text { Admin } & \text { merekap } \\
\text { laporan } & \text { hasil } \\
\text { pengaduan } & \text { dari } \\
\text { petugas satpol PP } & \\
\end{array}$ & Admin & $\begin{array}{l}\text { Merekap Laporan } \\
\text { Hasil Pengaduan }\end{array}$ \\
\hline 8 & $\begin{array}{l}\text { Kepala Satpol PP } \\
\text { memeriksa rekapan }\end{array}$ & $\begin{array}{l}\text { Kepala Satpol } \\
\text { PP }\end{array}$ & $\begin{array}{l}\text { Memeriksa } \\
\text { Laporan }\end{array}$ \\
\hline
\end{tabular}


Journal of Computer and Information Systems Ampera

Vol. 3, No. 1, January 2022 e-ISSN: 2775-2496

https://journal-computing.org/index.php/journal-cisa/index

laporan hasil
pengaduan

Dari penjelasan proses bisnis pada tabel 1. diatas, maka dapat digambarkan bagaimana diagram business use case yang terbentuk. Adapaun diagram business use case yang terbentuk dilihat pada gambar 1 berikut ini.

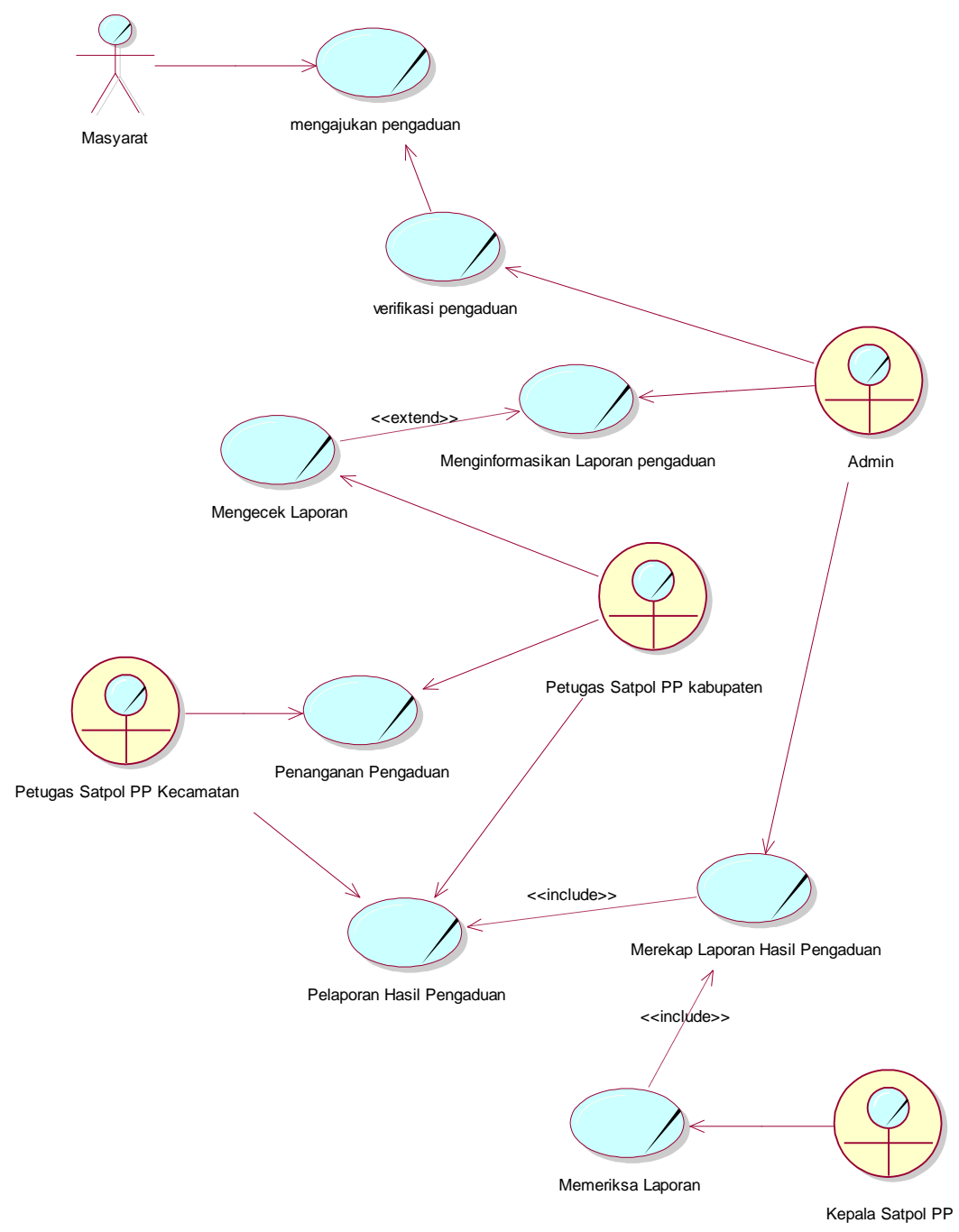

Gambar 1. Diagram Bussiness Use Case 
Vol. 3, No. 1, January 2022 e-ISSN: 2775-2496

https://journal-computing.org/index.php/journal-cisa/index

\subsection{Sistem Use Case Diagram}

Diagram Sistem Use Case akan menjelaskan mengenai siapa saja yang telibat dalam sistem (Aktor) dan apa saja yang dikerjakan oleh sistem (Use Case). Adapaun Diagram Sistem use case yang terbentuk dilihat pada gambar 2. berikut.

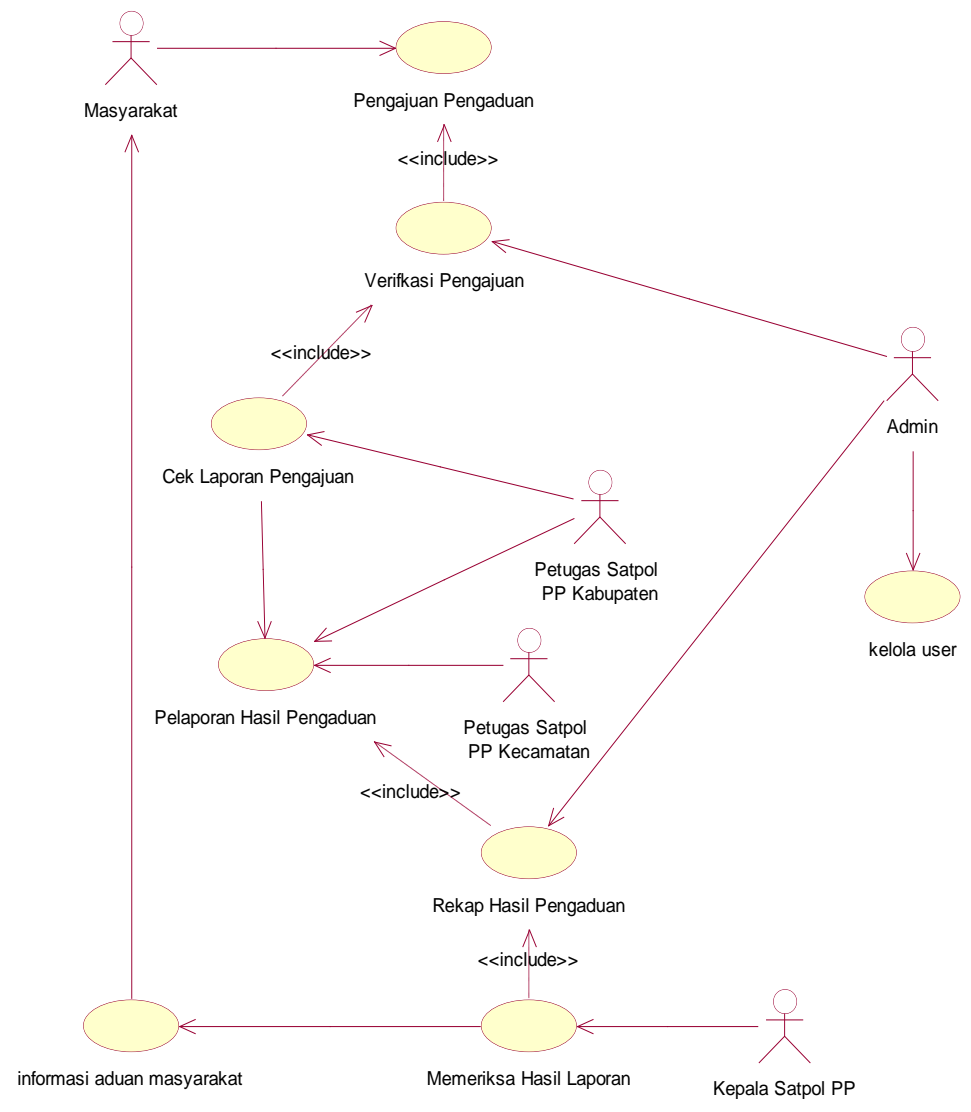

Gambar 2. Diagram System Use Case

\subsection{Relasi Tabel}

Relasi tabel yang terbentuk data database untuk pembuatan pengelolaan pengaduan masyarakat pada satpol pp kudus dilihar pada gambar 3 . 
Vol. 3, No. 1, January 2022 e-ISSN: 2775-2496

https://journal-computing.org/index.php/journal-cisa/index

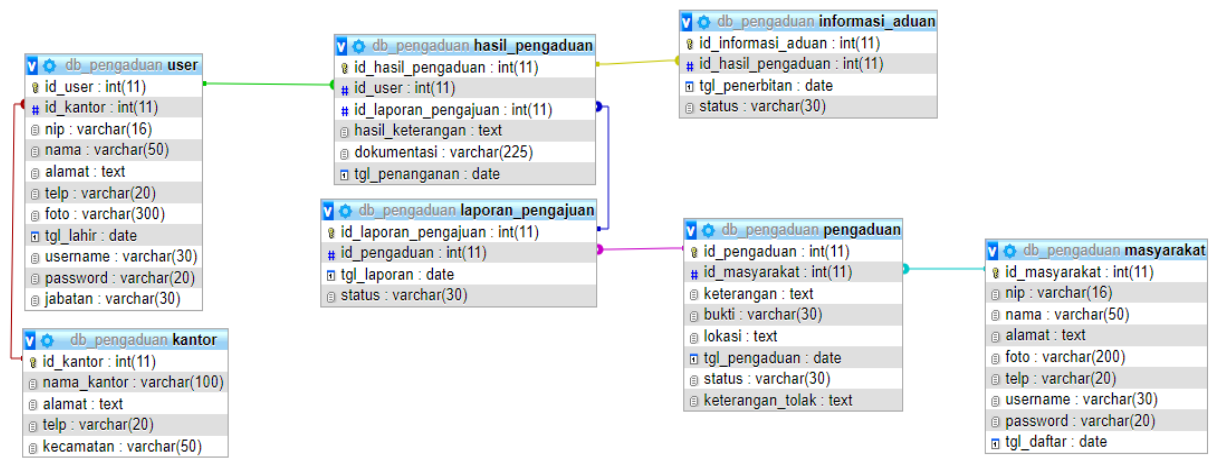

Gambar 3. Relasi Tabel

\subsection{Tampilan Sistem}

1) Halaman Login Masyarakat

Halaman dashboard login masyarakat merupakan halaman yang digunakan masyarakat untuk mengakses kedalam system pengaduan kejadian Kabupaten Kudus. Tampilan Halaman Login Masyarakat dilihat pada gambar 4 .

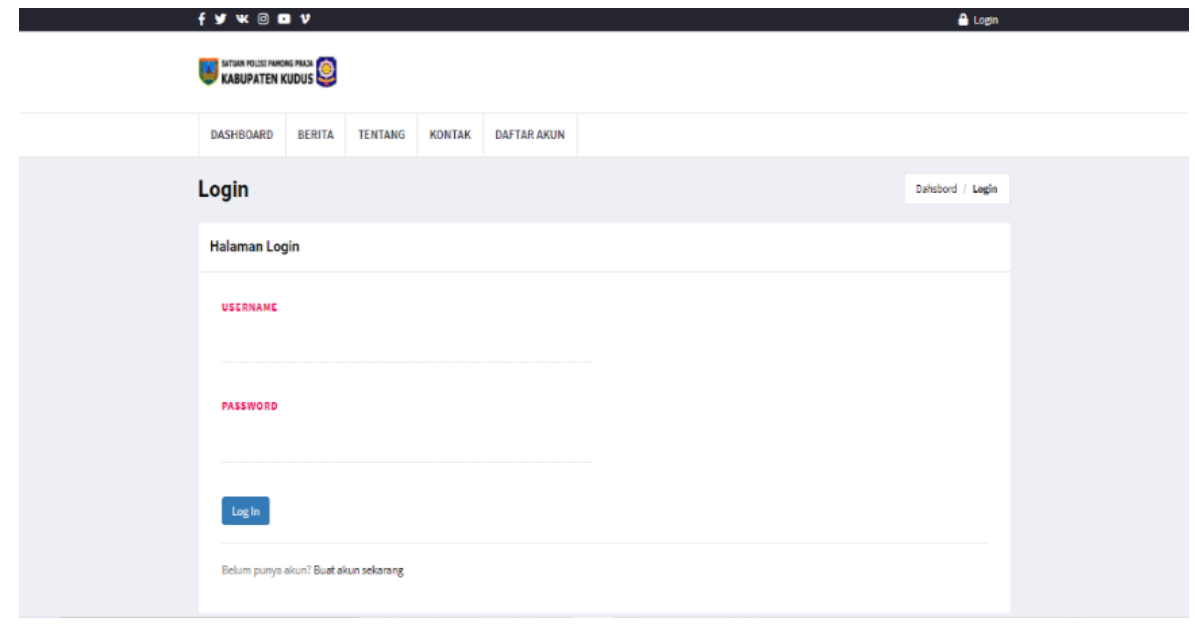

Gambar 4. Halaman Login Masyarakat

2) Halaman Penggaduan

Halaman pengaduan merupakan halaman yang digunakna untuk memberitahukan pengaduan masyarakat pada Satpol PP Kabupaten serta 
Vol. 3, No. 1, January 2022 e-ISSN: 2775-2496

https://journal-computing.org/index.php/journal-cisa/index

digunakna Satpol PP Kabupaten untuk menanggani pengaduan masyarakat. Halaman penggaduan dilihat pada gambar 5 .

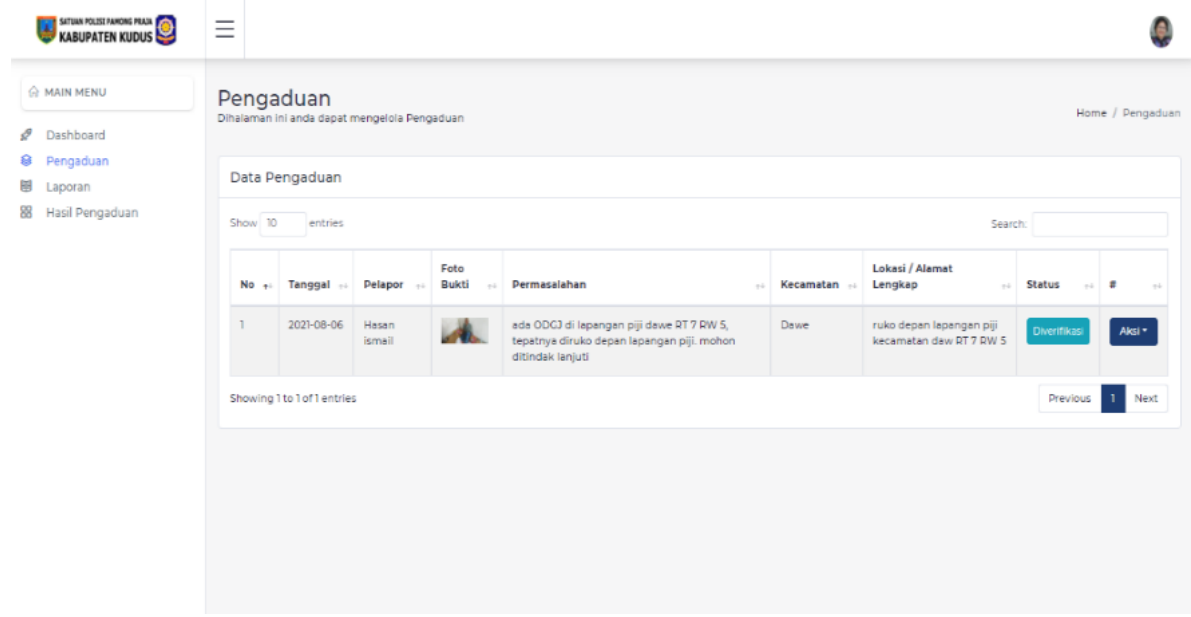

Gambar 5. Halaman Login Masyarakat

\section{KESIMPULAN}

Dari hasil analisa dan perancangan, serta implementasi serta pembahasan sebelumnya, maka penulis dapat memberi simpulan berikut:

1) Sistem yang dibuat untuk mengelola manajemen pengelolaan pengaduan Kabupaten Kudus.

2) Sistem meliputi pengelolaan data pengaduan, data penanganan pengaduan, data user, data kantor, laporan penanganan.

3) Informasi output sistem ini berupa laporan yang berkaitan dengan penanganan pengaduan dengan menggunakan notifikasi WhatsApp di sistem ini sebagai informasi masyarakat untuk mengetahui penanganan pengaduan.

4) Sistem yang dibuat menggunakan perancangan UML dengan metode pengembangan waterfall dan bahasa yang digunakan yaitu bahasa pemograman PHP dan menggunakan database MySQL.

\section{DAFTAR PUSTAKA}

[1] Anofrizen, Anofrizen. "Sistem Informasi Pengaduan Masyarakat Program Keluarga Harapan Kota Pekanbaru (Studi Kasus: Dinas Sosial dan 
Pemakaman Kota Pekanbaru)." Jurnal Ilmiah Rekayasa dan Manajemen Sistem Informasi 3, no. 1 (2017): 97-101.

[2] Boylle, Bonafasius Ade Mas, and Wibowo Arninputranto."Sistem Informasi Pengaduan Dengan Web Responsive di PT Pelabuhan Indonesia III Cabang Tanjung Perak." JURNAL ELTEK 12, no. 2 (2017): 53-64.

[3] Firmansyah, Yoki, Reza Maulana, and Nadiyah Fatin."Sistem Informasi Pengaduan Warga Berbasis Website." Jurnal Cendikia 19, no. 1 (2020): 397-404.

[4] Ibrahim, Adelina, and Arisandy Ambarita."Sistem Informasi Pengaduan Pelanggan Air Berbasis Website Pada PDAM Kota Ternate." IJIS-Indonesian Journal On Information System 3, no. 1 (2018).

[5] Ibrahim, Wahyu Hidayat, and Idria Maita."Sistem Informasi Pelayanan Publik Berbasis Web Pada Dinas Pekerjaan Umum Kabupaten Kampar." Jurnal Ilmiah Rekayasa dan Manajemen Sistem Informasi 3, no. 2 (2017): 17-22.

[6] Sukamto, R. A., M. Shalahuddin (2018). Rekayasa Perangkat Lunak Terstruktur dan Berorientasi Objek. Bandung: Informatika.

[7] Hendini, Ade. "Pemodelan UML sistem informasi monitoring penjualan dan stok barang (studi kasus: distro zhezha pontianak)." Jurnal Khatulistiwa Informatika 4.2 (2016).

[8] Wijayanti, Trendy. "Sistem Informasi Pengaduan Masyarakat pada Kecamatan Dawe Berbasis Web”.(2021) 